\title{
Fabrication of strong long-period gratings in hydrogen-free fibers with 157-nm $F_{2}$-laser radiation
}

\author{
Kevin P. Chen, Peter R. Herman, and Jie Zhang \\ Department of Electrical and Computer Engineering, University of Toronto, 10 Kings College Road, Toronto, Ontario M5S 3G4, Canada
}

Robin Tam

Photonics Research Ontario, 60 St. George Street, Toronto, Ontario M5S 1A7, Canada

Received January 3, 2001

\begin{abstract}
Long-period gratings were fabricated in standard telecommunication fiber (Corning SMF-28) by use of what is believed to be record short-wavelength light from a 157-nm $\mathrm{F}_{2}$ laser. Strong loss peaks were formed without the need for enhancement techniques such as hydrogen loading. The magnitude of the attenuation peak was sensitive to the single-pulse laser fluence, decreasing with increasing pulse fluence as a result of nonuniform 157-nm laser interaction with both the fiber cladding and core. The long-period fiber gratings have good wavelength stability $(\Delta \lambda \sim 7 \mathrm{~nm})$ under thermal annealing at $150^{\circ} \mathrm{C}$. (C) 2001 Optical Society of America

OCIS codes: $220.4610,060.2270,060.2370$.
\end{abstract}

Photosensitivity enhancement techniques such as hydrogen loading ${ }^{1}$ are widely applied today to improve the weak ultraviolet laser interaction of standard telecommunication fiber for the fabrication of fiber Bragg gratings, long-period fiber gratings (LPFGs), and other useful photonic structures. Shorter-wavelength laser sources offer an alternative route to photosensitivity enhancement that is especially attractive in terms of access to new absorption channels. Albert et $a .^{2}{ }^{2}$ demonstrated an approximately tenfold improvement in refractive-index modification inside a low- $\mathrm{GeO}_{2}$ fiber by shifting the laser wavelength from 248 to $193 \mathrm{~nm}$. Two-photon absorption across the $\mathrm{GeO}_{2}$ bandgap was the inferred photosensitivity mechanism. Our group has further extended such studies to what is believed to be the record short wavelength of $157 \mathrm{~nm}$ (Refs. 3-5), with the aim of gaining access to new single-photon processes near the band edge of $\mathrm{GeO}_{2}$ and fused-silica glasses.

The $\mathrm{F}_{2}$ laser produces $7.9-\mathrm{eV}$ photons that are known $^{6}$ to damage ultraviolet-grade fused-silica glasses in long exposures, possibly through absorption involving three- and four-member silicon-ring structures. $^{7}$ In low- $\mathrm{GeO}_{2}$ (i.e., 5\%) glasses, the $157-\mathrm{nm}$ photons directly bridge the $\sim 7.1-\mathrm{eV}$ bandgap, ${ }^{8}$ which allows access to strong single-photon photosensitivity mechanisms without the need for traditional enhancement techniques. ${ }^{3-5}$ In this Letter we describe, for what is to our knowledge the first time, the formation of strong and good-quality LPFGs in standard single-mode fibers (Corning SMF-28) without fiber pretreatment. The $\mathrm{F}_{2}$-laser photosensitivity response is comparable with that of $248-\mathrm{nm}$ radiated fibers presoaked in hydrogen.

The $157-\mathrm{nm}$ radiation was provided by a $\mathrm{F}_{2}$ laser (Lambda Physik LPF 220) operated at $100-\mathrm{Hz}$ repetition rate. The 15-ns pulses passed through an airtight processing vessel that we flushed with 1-atm argon gas to eliminate 157-nm absorption by air. We selected a uniform portion $(20 \mathrm{~mm} \times 2.45 \mathrm{~mm})$ of the beam to illuminate a stainless-steel amplitude-grating mask of $304-\mu \mathrm{m}$ period $(152-\mu \mathrm{m}$ lines and gaps). Standard telecommunication fiber (Corning SMF 28) mounted $2 \mathrm{~mm}$ behind the amplitude mask minimized mask contamination. The geometry provided single-pulse laser fluence in the range $1-5 \mathrm{~mJ} / \mathrm{cm}^{2}$ along the full $20-\mathrm{mm}$ exposure length of fiber and produced 66 line-and-space pairs in the LPFG. Single-pulse fluence up to $150 \mathrm{~mJ} / \mathrm{cm}^{2}$ was also applied by concentration of the laser beam with a $\mathrm{MgF}_{2}$ lens ( $\sim 6-\mathrm{cm}$ focal length) and translation of the fiber-mask assembly with a motorized stage. The transmission spectrum of each LPFG was monitored in situ during the laser exposure with unpolarized infrared light and an optical spectrum analyzer (Ando $\mathrm{AQ6531E)} \mathrm{set} \mathrm{at} \mathrm{5-nm} \mathrm{resolution.}$

The infrared transmission spectrum of a LPFG as recorded at the point of maximum attenuation is shown in Fig. 1. The 17-dB loss peak at $1434 \mathrm{~nm}$ was

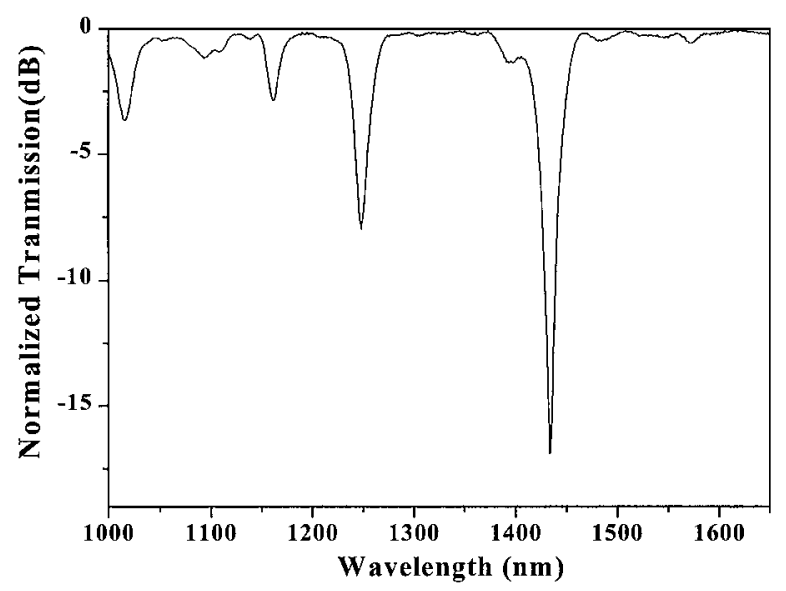

Fig. 1. Normalized transmission spectrum of a 20-mm-long LPFG fabricated in untreated SMF-28 fiber with $157-\mathrm{nm} \mathrm{F}_{2}$-laser radiation. The single-pulse and total accumulated fluence were $2.7 \mathrm{~mJ} / \mathrm{cm}^{2}$ and $2.7 \mathrm{~kJ} / \mathrm{cm}^{2}$, respectively. 
formed with a $2.7-\mathrm{kJ} / \mathrm{cm}^{2}$ fluence dose $\left(2.7 \mathrm{~mJ} / \mathrm{cm}^{2}\right.$ per pulse). The out-of-band loss of $<0.4-\mathrm{dB}$ is similar to what is typically reported for LPFGs fabricated in hydrogen-soaked fibers with ultravioletlaser sources. ${ }^{9}$ To our best knowledge, this is the strongest LPFG formed with an excimer-laser source in low- $\mathrm{GeO}_{2}$ telecommunication fiber without any pretreatment. Although researchers recently applied high-power, high-intensity $\mathrm{CO}_{2}$-laser ${ }^{10}$ and femtosecond-laser ${ }^{11}$ radiation to hydrogen-free fibers to fabricate strong LPFGs, thermal damage and large out-of-band losses preclude practical consideration of these alternative laser approaches. The present results therefore attest to strong fundamental interaction of $157-\mathrm{nm}$ radiation with low- $\mathrm{GeO}_{2}$ glasses and suggest a practical $\mathrm{F}_{2}$-laser application in the formation of LPFGs.

Figure 2 shows the development of the principal loss peak as a function of the accumulated 157-nm laser fluence for a single-pulse fluence of $2.5 \mathrm{~mJ} / \mathrm{cm}^{2}$. A 50-nm shift of the resonance peak to the longer wavelength evolves smoothly [Fig. 2(a)] over the $4.8-\mathrm{kJ} / \mathrm{cm}^{2}$ exposure. A peak $16-\mathrm{dB}$ loss is noted at the 1432-nm wavelength, midway through the exposure, before the peak drops to $\sim 2 \mathrm{~dB}$ at full exposure [Fig. 2(b)]. These responses are consistent with theory, with the resonance peak intensity following a sinc-squared function of the coupling coefficient between the fiber core mode and the cladding modes. ${ }^{9}$

The maximum attainable transmission loss decreases with an increase in the single-pulse $\mathrm{F}_{2}$-laser, fluence, as illustrated in Fig. 3. Reproduced from Fig. 1 is the $17-\mathrm{dB}$ loss peak at 1434-nm, developed with a total dose of $2.7 \mathrm{~kJ} / \mathrm{cm}^{2}$ when $2.7-\mathrm{mJ} / \mathrm{cm}^{2}$ single-pulse fluence is used. A total 167-min exposure was required for this $100-\mathrm{Hz}$ exposure. This spectrum is compared with a maximum $8-\mathrm{dB}$ attenuation peak at $\sim 1520-\mathrm{nm}$ wavelength, which was formed by use of an average single-pulse fluence of $\sim 43 \mathrm{~mJ} / \mathrm{cm}^{2}$. A fivefold-larger exposure of $\sim 10 \mathrm{~kJ} / \mathrm{cm}^{2}$ was required. With larger single-pulse fluence of $84 \mathrm{~mJ} / \mathrm{cm}^{2}$, the peak loss decreases to only $4 \mathrm{~dB}$. Such significant decibel falloff in the resonance attenuation points to an important trade-off in 157-nm photosensitivity applications: Low laser fluence provides strong and damage-free photosensitivity responses, at the expense of longer exposure times.

Laser-induced modification of and damage to the $\mathrm{GeO}_{2}$ glasses is principally responsible for a lowfluence $\mathrm{F}_{2}$-laser processing window for fabrication of LPFGs. In photosensitivity studies of $\mathrm{GeO}_{2}$ planar waveguides without cladding, ${ }^{4}$ the $157-\mathrm{nm}$ penetration depth in the low- $\mathrm{GeO}_{2}(3 \%)$ core was inferred to shrink from $\sim 8$ to $4 \mu \mathrm{m}$ during a total $22-\mathrm{kJ} / \mathrm{cm}^{2}$ exposure at $\sim 7.5-\mathrm{mJ} / \mathrm{cm}^{2}$ single-pulse fluence. This shrinking points to nonuniform modification of both the 157-nm absorption and the refractive index in the present LPFGs. The planar-waveguide experiments ${ }^{4}$ and our laser-grating trimming experiments also predict an $\sim 5 \times 10^{-4}$ change in the effective refractive index of the LPFG fiber produced at low fluence shown in Fig. 3. The experimental evidence suggests that larger single-pulse fluence (i.e., tens of millijoules per square centimeter) accelerates the glass modification, eventually localizing the refractive-index change to the cladding-core interface. Consequently, energy exchange between the guiding and the cladding modes is reduced, weakening the loss peaks in the LPFG. Further evidence for such nonuniform refractive-index modification is the asymmetric scattering of coupled $\mathrm{He}-\mathrm{Ne}$-laser light, which is always strongest when viewed from the $\mathrm{F}_{2}$-laser-exposed side of the LPFG fiber. Further, this scattered light is evident only from within longitudinal slices of the fiber that were exposed to the $157-\mathrm{nm}$ radiation, which is evidence of bulk $157-\mathrm{nm}$ laser damage to the 157-nm-exposed cladding. Such damage is apparently not significant in light of the low, <0.4-dB, out-of-band losses shown in Fig. 1.

The fused-silica cladding of the fiber is also photosensitive under $\mathrm{F}_{2}$-laser exposure and is expected to contribute to LPFG efficiency. $\mathrm{A} \mathrm{F}_{2}$-laser study ${ }^{4}$ of bulk fused silica (Corning 7940) showed a 157-nm penetration depth of $\sim 0.4-\mathrm{mm}$ and a refractive-index response of $\Delta n=4.6 \times 10^{-5}(N F)^{0.55}$, where $N$ is the

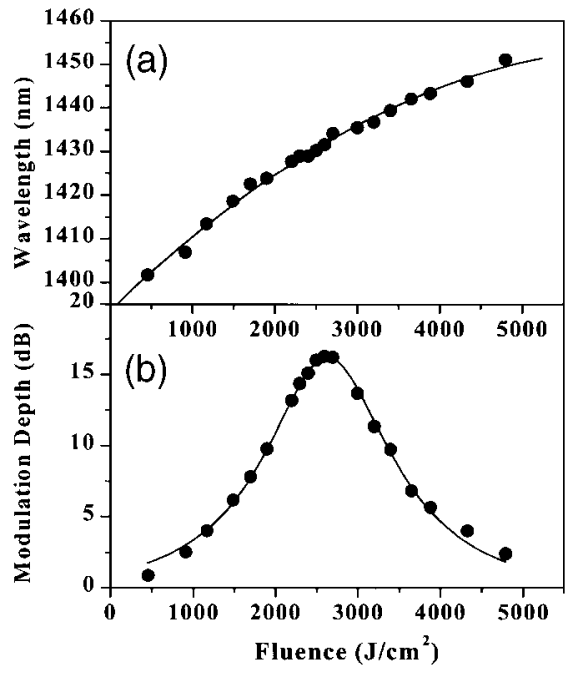

Fig. 2. (a) Center wavelength and (b) transmission loss of the strongest LPFG resonance peak as a function of the accumulated $\mathrm{F}_{2}$-laser fluence. The single-pulse fluence was $2.7 \mathrm{~mJ} / \mathrm{cm}^{2}$.

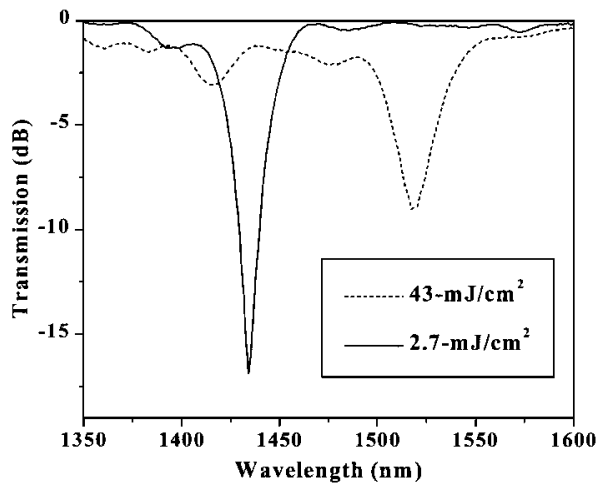

Fig. 3. Transmission spectra of the LPFG resonance peak at the point of maximum attenuation: single-pulse fluences of 2.7 and $43 \mathrm{~mJ} / \mathrm{cm}^{2}$ are shown. 


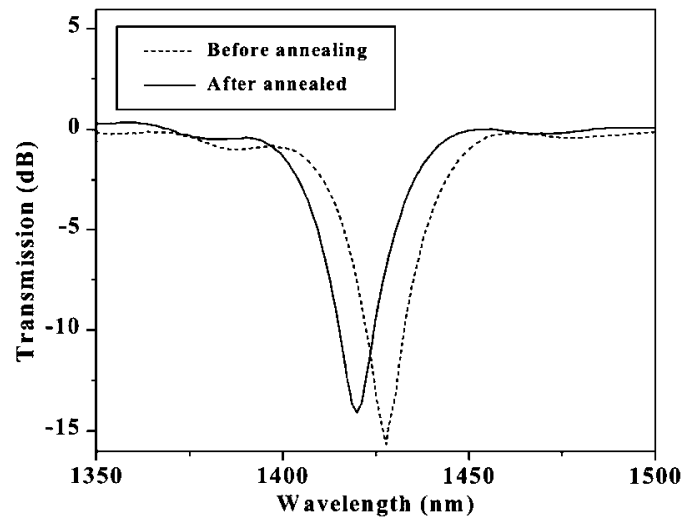

Fig. 4. 7-nm wavelength shift of a LPFG attenuation peak following 24 -h annealing at $150{ }^{\circ} \mathrm{C}$. The LPFG was formed with a single-pulse fluence of $2.4-\mathrm{mJ} / \mathrm{cm}^{2}$ and a $1.9-\mathrm{kJ} / \mathrm{cm}^{2}$ total dose.

total number of laser pulses and $F$ is the single-pulse fluence in kilijoules per square centimeter. This result indicates that a $\Delta n$ of $\sim 0.8 \times 10^{-4}$ was induced in the cladding for the LPFG shown in Fig. 1, a value only sixfold smaller than the anticipated refractiveindex change in the core. ${ }^{4}$

One important advantage of $\mathrm{F}_{2}$-laser-formed LPFGs is their intrinsic wavelength stability compared with that of LPFGs fabricated in hydrogen-soaked fiber. Figure 4 shows the resonance loss peak of a $\mathrm{F}_{2}$-laser-formed LPFG before and after thermal annealing at $150{ }^{\circ} \mathrm{C}$ for $24 \mathrm{~h}$. Annealing produces a 7-nm wavelength shift and a 2 -dB decrease in the peak strength. These results compare favorably with the $\sim 30$-nm wavelength shift and larger drop in strength for thermally annealed $\left(100^{\circ} \mathrm{C}\right) \mathrm{LPFGs}$ fabricated in a hydrogen-soaked fiber under 248-nm laser radiation that were reported in Ref. 9.

In related work, we have also shown that the $\mathrm{F}_{2}$-laser photosensitivity response in SMF-28 fiber is dramatically enhanced by 500 times when hydrogen soaking is applied. ${ }^{5}$ Comparison with 248-nm-exposed hydrogen-soaked fibers also revealed a $>250$-fold enhancement of the 157-nm response. Such strong enhancement by hydrogen of $\mathrm{F}_{2}$-laser light is only apparent in LPFGs; only threefold enhance- ment of the 157-nm laser-induced refractive-index change was noted in hydrogen-soaked $\mathrm{GeO}_{2}$ waveguides $\left(3 \% \mathrm{GeO}_{2}\right)$. The contrasting enhancement is attributed to the strong $157-\mathrm{nm}$ photosensitivity responses in the hydrogen-soaked cladding, which sensitively affect the efficiency of LPFGs.

In conclusion, strong and high-quality LPFGs were formed for what is believed to be the first time without fiber-sensitization techniques by use of what is to our knowledge record short-wavelength $157-\mathrm{nm}$ radiation. The hydrogen-free gratings offer excellent wavelength stability. However, a low-fluence-processing window $\left(\sim 5 \mathrm{~mJ} / \mathrm{cm}^{2}\right)$ appears necessary to avoid fiber damage.

Financial support from the Natural Science and Engineering Research Council of Canada and the Canadian Institute for Photonics Innovation is gratefully acknowledged. K. P. Chen's e-mail address is kevinc@ecf.utoronto.ca.

\section{References}

1. P. J. Lemaire, R. M. Atkins, V. Mizrahi, and W. A. Reed, Electron. Lett. 29, 1191 (1993).

2. J. Albert, B. Malo, K. O. Hill, F. Bilodeau, and D. C. Johnson, Appl. Phys. Lett. 67, 3529 (1995).

3. P. R. Herman and K. Beckley, in Conference on Lasers and Electro-Optics, Vol. 11 of 1997 OSA Technical Digest Series (Optical Society of America, Washington, D.C., 1997), paper CTuN3.

4. P. R. Herman, K. P. Chen, P. Corkum, A. Naumov, S. Ng, and J. Zhang, Proc. SPIE 4088, 345 (2000).

5. K. P. Chen, P. R. Herman, R. Tam, and J. Zhang, Electron. Lett. 36, 2000 (2000).

6. V. Liberman, T. M. Bloomstein, M. Rothschild, J. H. C. Sedlacek, R. S. Uttaro, A. K. Bates, C. Van Peski, and K. Orvek, J. Vac. Sci. Technol. B 17, 3273 (1999).

7. H. Hosono, M. Mizuguchi, L. Skuja, and T. Ogawa, Opt. Lett. 24, 1549 (1999).

8. J. Nishii, N. Kitamura, H. Yamanaka, H. Hosono, and H. Kawazoe, Opt. Lett. 20, 1184 (1995).

9. A. M. Vengsakar, P. J. Lemaire, J. B. Judkins, V. Bhatia, T. Erdogan, and J. E. Sipe, J. Lightwave Technol. 14, 58 (1996).

10. D. D. Davis, T. K. Gaylord, E. N. Glytsis, S. G. Kosinski, S. C. Mettler, and A. M. Vengsarkar, Electron. Lett. 34, 302 (1998).

11. Y. Kondo, K. Nouchi, T. Mitsuyu, M. Watanabe, P. G. Kazansky, and K. Hirao, Opt. Lett. 24, 646 (1999). 